\title{
The effect of intermittent positive pressure breathing on lung volumes in acute quadriparesis
}

\author{
K Stiller BAppSc, ${ }^{1}$ R Simionato BAppSc, ${ }^{1} \mathrm{~K}$ Rice BSc BAppSc, ${ }^{1}$ B Hall BSc $\mathrm{MSc}^{2}$ \\ ${ }^{1}$ Physiotherapy Department, Royal Adelaide Hospital, North Terrace Adelaide, South \\ Australia, 5000, ${ }^{2}$ Lecturer in Statistics, University of South Australia.
}

\begin{abstract}
Resting tidal volume and vital capacity were measured daily in 5 patients with acute quadriparesis during the first 7 to 10 days of their hospitalisation. On admission, vital capacity was significantly reduced to $26 \%$ of the predicted value $(p<0.001)$. This increased significantly over the study period to $33 \%$ of the predicted value $(p<0.02)$. Expiratory flow rates, measured on one occasion during the study period, showed similar decrements.

Tidal volume and vital capacity were also measured immediately following administration of intermittent positive pressure breathing (IPPB). Although the lung volume achieved during IPPB was significantly higher than resting values of tidal volume and vital capacity $(p<0.001)$, tidal volume returned to baseline values as soon as IPPB was ceased. Vital capacity remained significantly higher than baseline values at this stage $(p<0.02)$, although the mean increase in vital capacity immediately following IPPB was only $43 \mathrm{mls}$.

Acute quadriparesis is associated with a severe ventilatory impairment which includes a reduced vital capacity and expiratory flow rates. IPPB has a positive effect on lung volumes whilst it is being administered. Immediately following treatment, this effect does not appear to be sustained at a level which would be considered clinically significant.
\end{abstract}

Key words: intermittent positive pressure breathing; lung volume; quadriparesis.

\section{Introduction}

Traumatic transection of the spinal cord results in paralysis of muscles innervated by both the damaged spinal segment and all segments below this level. Consequently, with transection of the spinal cord in the cervical region, quadriparesis results. Inspiratory ability of such patients is compromised by the denervation of the intercostal muscles, leaving the diaphragm and accessory muscles as the muscles of inspiration. Consequently, there is a marked reduction in the ability of quadriplegics to achieve full lung inflation, which predisposes them to the development of alveolar hypoventilation. In addition, expiratory ability, particularly forced expiratory manoeuvres (eg coughing), are adversely af- fected, as they rely on intercostal and abdominal muscle activity, as well as passive recoil of the lung and chest wall. Thus, quadriplegics have a decreased ability to clear pulmonary secretions which may lead to sputum retention. As a result, atelectasis, hypoxia and bronchopulmonary infection may develop. ${ }^{1,2}$ In fact, in the acute stage, respiratory complications may be responsible for as many as half of the deaths in patients with complete quadriparesis. ${ }^{1}$

Pulmonary function tests performed on complete quadriplegics have revealed significant reductions in static lung volumes when compared to predicted normal values. Ledsome and Sharp, ${ }^{3}$ investigating 11 quadriplegics during the first week following injury, found that forced vital capacity (FVC), forced expiratory volume in one 
second $\left(\mathrm{FEV}_{1}\right)$ and maximal mid expiratory flow rate (MMEFR) were significantly reduced to approximately $30 \%$ of predicted normal values. Rose and colleagues, ${ }^{4}$ in a study of 12 quadriplegics, 4 to 15 months post injury, found that vital capacity (VC), $\mathrm{FEV}_{1}$ and peak expiratory flow rate (PEFR) were all reduced to approximately $43 \%$ of predicted values. These results have been supported by similar studies. ${ }^{3,5-7}$

From the first day of admission to hospital, spinal injured patients routinely receive chest physiotherapy as part of their overall medical care. The aims of chest physiotherapy are to prevent or treat the respiratory complications outlined earlier, by the use of a number of techniques that are thought to increase inspiratory volumes and maximise expiratory effort. This may include the use of intermittent positive pressure breathing (IPPB) and 'breathing exercises' to improve pulmonary ventilation, and assisted coughing and other physiotherapy techniques to aid in the clearance of pulmonary secretions. To date, there have been no controlled studies examining the efficacy of chest physiotherapy in achieving these aims.

The effect of IPPB on patients with acute quadriparesis does not appear to have been scientifically evaluated. A number of studies have assessed the use of IPPB on patients with chronic neuromuscular weakness affecting respiratory musles. ${ }^{7,8}$ Included in these studies were a number of patients with chronic quadriparesis. No immediate significant improvements in lung volumes or pulmonary compliance were found.

The aims of this pilot study were, firstly, to document selected lung volumes of patients with cervical cord transection during the first 7 to 10 days following their injury; and, secondly, to examine the immediate effect of IPPB on lung volumes during this acute stage.

\section{Materials and methods}

Patients admitted to the Spinal Injuries Unit (SIU) of the Royal Adelaide Hospital (RAH), from 1.8 .88 to 1.2 .89 , with acute traumatic transection of the cervical cord and resultant quadriparesis were included in the study. Patients were excluded if admission to the SIU was delayed more than 24 hours post injury, or if their mental state was such that they were unable to cooperate with the treatment or testing procedure. The patient's age, sex, height, relevant past history, date and nature of injury, surgical procedures since admission and medical status were noted. Any changes in these variables were recorded at subsequent visits.

Each patient was seen within 24 hours of admission to the SIU, at which time tidal volume (TV) and VC were recorded (to the nearest $50 \mathrm{mls}$ ). A calibrated Wright's spirometer was used for these and subsequent recordings of lung volumes. The best of 3 attempts at VC was recorded. Predicted values for $\mathrm{VC}$, based on normal values for sex, age and height were calculated. ${ }^{9}$

Treatment with IPPB was commenced on the day of admission. The ventilator used was a Bird Mark 14, with breaths administered via a mouthpiece. The inspiratory pressure limit was set at the maximum value which the patient could tolerate. The IPPB treatment, performed every 2 hours, consisted of 4 repetitions of 6 breaths using the ventilator, interspersed with a period of 30-60 seconds of relaxed natural breathing.

Recordings of TV and VC were taken prior to, and immediately at the completion of the IPPB treatment. The readings taken prior to use of IPPB have been considered as the resting values. During the second repetition of IPPB breaths, the spirometer was attached to the exhale valve of the ventilator and the mean volume administered during IPPB recorded. The airway pressure, taken from the Bird ventilator, was also recorded during IPPB. These measurements were taken daily, on weekdays, for the first 7 to 10 days of the patient's hospitalisation. In addition, on one occasion only during the study period, each patient performed a FVC manoeuvre on a calibrated Vitalograph compact spirometer, and various expiratory flow rates were measured.

Routine spinal nursing positions were not altered for the purpose of this study and the position remained constant during each testing procedure. All measurements, and 
IPPB treatment at the time of testing, were performed by the same physiotherapist throughout the study.

\section{Analysis of data}

Results are expressed as mean \pm standard deviation unless otherwise stated, and all statistical analyses were performed using the Students t-test. Comparisons not reaching a minimum level of significance of $p<0.05$ are recorded as being not significantly different.

\section{Results}

Five patients were included in the study. Their physical characteristics are shown in Table 1. All patients underwent closed reduction of their cervical spine injury on the day of admission to the RAH. Reduction was then maintained using Gardner Wells tongs with the patient resting in bed. All patients were medically stable throughout the study period. Two other patients were excluded from the study, due to late admission to the SIU.

In Figures 1 to 5 the sequential measurements of both resting and post-IPPB TV and $\mathrm{VC}$ are plotted for each subject, along with the volumes achieved during IPPB at these time points.

It can be seen from Table I and Figures 1 to 5 that each of the 5 patients included in this study had highly significant reductions of resting $\mathrm{VC}$, compared to predicted normal values, when measured within 24 hours of admission to the SIU (group mean $26 \pm 7 \%$ predicted, $p<0.001$ ). It is apparent from Figures 1 to 5 that in general, there was an upward trend in VC over the subsequent 7 to 10 days for each subject. The mean VC for the group significantly increased to reach $33 \pm 6 \%$ of the predicted normal value $(p<0.02)$.

The expiratory flow rates, measured on one occasion only, were also reduced for every patient. PEFR was reduced on average to $23 \pm 6 \%$ of the predicted value. Other flow rates showed similar decrements (Table II).

On the whole, the volume achieved during IPPB showed some consistency for each subject. The exception to this was subject 3 (Fig 3), where this volume was less than the resting $\mathrm{VC}$, for reasons that are unclear. The group mean volume during IPPB was significantly higher than the group mean resting values of both $\mathrm{TV}$ and VC $(p<$ 0.001 ) (Figs 1-5). Even though the inspiratory pressure limit was set at the maximum value which the patient could tolerate (group mean $19 \pm 2 \mathrm{~cm} \mathrm{H}_{2} 0$ ) this volume only reached, at best, $60 \%$ of the predicted normal VC value (Fig 1).

Immediately post IPPB, TV was not significantly different from resting levels. Overall, the mean increase in VC from resting levels immediately following IPPB for the group was $43 \pm 89 \mathrm{mls}$, which was significant $(p<0.02)$. When individual subjects were examined, it can be seen that

Table I Patient Characteristics

\begin{tabular}{|c|c|c|c|c|c|c|c|c|}
\hline $\begin{array}{l}\text { Subject } \\
\text { number }\end{array}$ & $\begin{array}{l}\text { Age } \\
\text { yrs }\end{array}$ & Sex & $\begin{array}{c}\text { Height } \\
\mathrm{cm}\end{array}$ & $\begin{array}{c}\text { Level of } \\
\text { quadriparesis }\end{array}$ & $\begin{array}{c}\text { Past } \\
\text { history }\end{array}$ & $\begin{array}{c}\text { Duration } \\
\text { of injury } \\
\text { days }\end{array}$ & $\begin{array}{l}\text { Vital } \\
\text { litres }\end{array}$ & $\begin{array}{c}\text { Capacity } \\
\% \text { pred }\end{array}$ \\
\hline 1 & 41 & $\mathbf{M}$ & 175 & $\mathrm{C} 5 / 6$ & - & $\begin{array}{r}1 \\
10\end{array}$ & $\begin{array}{l}1.6 \\
1.9\end{array}$ & $\begin{array}{l}32 \\
38\end{array}$ \\
\hline 2 & 47 & $\mathrm{~F}$ & 163 & C7 & $\begin{array}{l}\text { smoker } \\
\text { 30/day }\end{array}$ & $\begin{array}{l}1 \\
7\end{array}$ & $\begin{array}{l}0.8 \\
1.35\end{array}$ & $\begin{array}{l}24 \\
40\end{array}$ \\
\hline 3 & 14 & $\mathrm{~F}$ & 166 & C5 & - & $\begin{array}{r}2 \\
10\end{array}$ & $\begin{array}{l}0.9 \\
1.3\end{array}$ & $\begin{array}{l}21 \\
31\end{array}$ \\
\hline 4 & 52 & $\mathbf{M}$ & 162 & C6/7 & - & $\begin{array}{r}1 \\
10\end{array}$ & $\begin{array}{l}1.4 \\
1.4\end{array}$ & $\begin{array}{l}35 \\
35\end{array}$ \\
\hline 5 & 16 & $\mathbf{M}$ & 187 & C5 & $\begin{array}{l}\text { smoker } \\
20 / \text { day }\end{array}$ & $\begin{array}{r}1 \\
10\end{array}$ & $\begin{array}{l}1.1 \\
1.4\end{array}$ & $\begin{array}{l}18 \\
22\end{array}$ \\
\hline
\end{tabular}



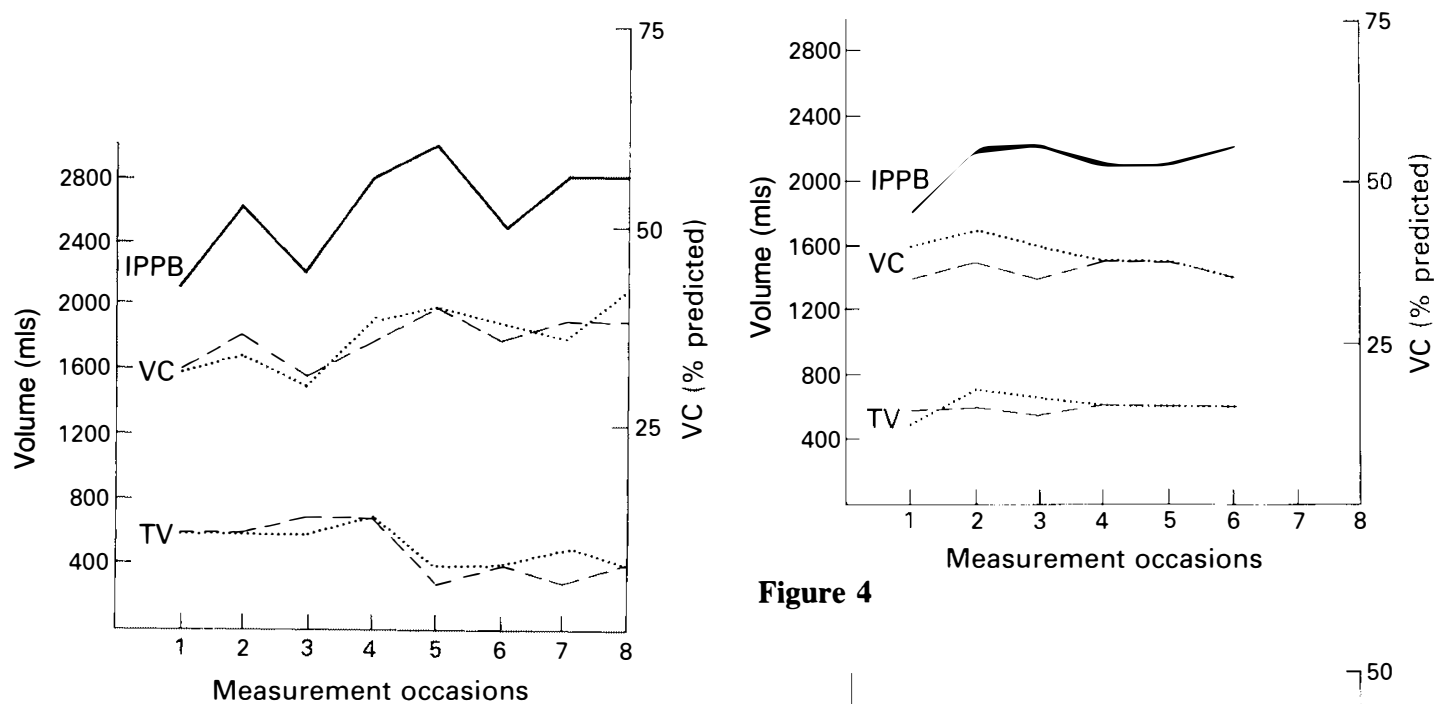

Figure 4

\section{Figure 1}

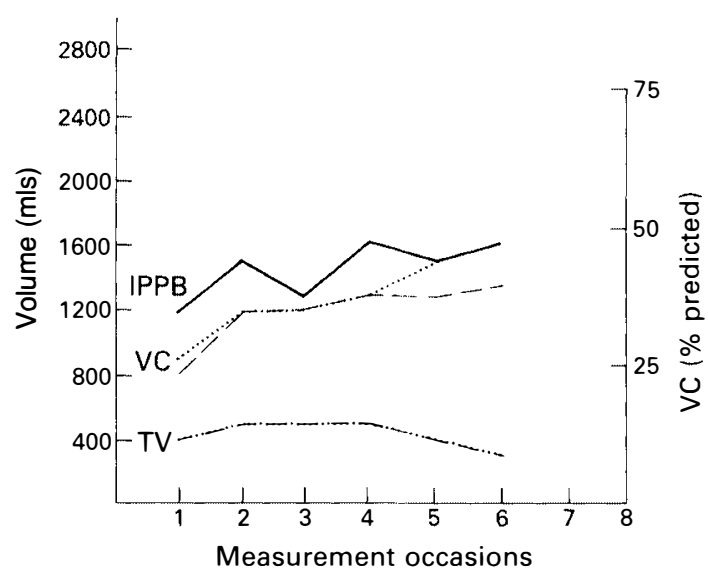

Figure 2

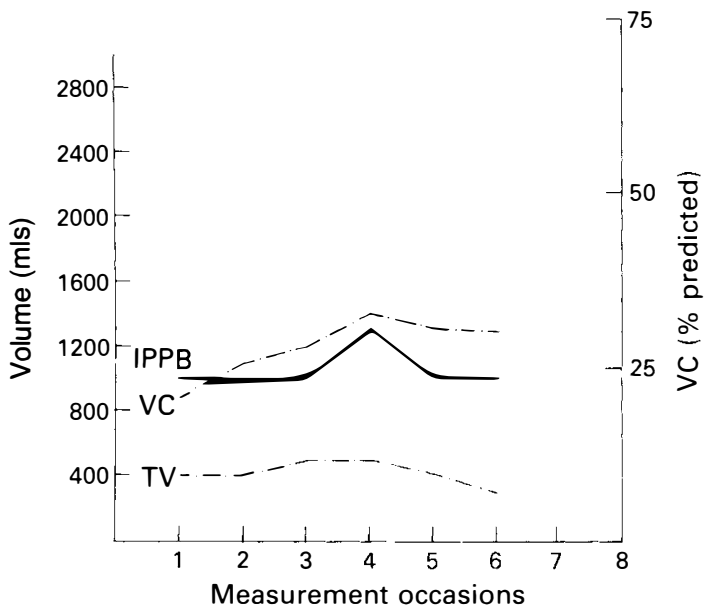

Figure 3

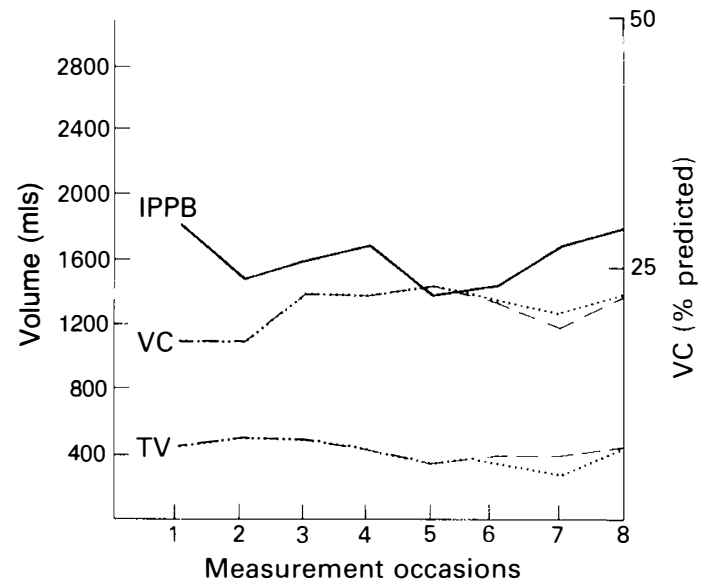

Figure 5

Figure 1-5 Resting and post-IPPB TV and VC, and volume achieved during IPPB, for subjects 1-5 respectively.

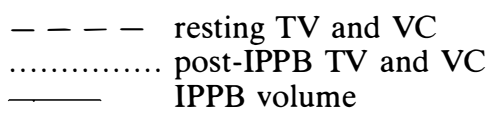

while the post-IPPB values of VC for subjects 2 to 5 were either equivalent to or greater than resting values, subject one demonstrated both positive and negative changes (Figs 1-5).

\section{Discussion}

The rationale for the use of IPPB in acute quadriparesis is based on the assumption that periodic hyperinflations delivered via a mechanical device may enable the patient to 
Table II Expiratory flow rates of quadriplegic patients

\begin{tabular}{|c|c|c|c|c|c|c|c|c|c|}
\hline \multirow{2}{*}{$\begin{array}{l}\text { Subject } \\
\text { number }\end{array}$} & \multirow{2}{*}{$\begin{array}{l}\text { Duration of } \\
\text { injury (days) }\end{array}$} & \multicolumn{2}{|c|}{$\mathrm{FEV}_{1}$} & \multicolumn{2}{|c|}{$\mathrm{FEV}_{1} / \mathrm{FVC}$} & \multirow{2}{*}{\multicolumn{2}{|c|}{$\begin{array}{c}\text { PEFR } \\
\text { litres/min \% pred }\end{array}$}} & \multicolumn{2}{|c|}{$\mathrm{FEF}_{25-75}$} \\
\hline & & litres & $\% \mathrm{p}$ & $\%$ & $\%$ pred & & & litres/s & $\%$ pred \\
\hline 1 & 2 & 1.30 & 32 & 83 & 100 & 124 & 22 & - & - \\
\hline 2 & 6 & 0.67 & 24 & 50 & 61 & 67 & 18 & 0.37 & 13 \\
\hline 3 & 10 & 0.94 & 25 & 68 & 76 & 102 & 22 & 0.40 & 8 \\
\hline 5 & 3 & 1.18 & 23 & 85 & 100 & 168 & 31 & 1.56 & 29 \\
\hline
\end{tabular}

Subject no. 4-no data, machine out of order

$\mathrm{FEV}_{1}=$ Forced expiratory volume in one second

$\mathrm{FVC}=$ Forced vital capacity

PEFR $=$ Peak expiratory flow rate

$\mathrm{FEF}_{25-75}=$ Forced expiratory flow rate between 25 and $75 \%$ of vital capacity

increase inspiratory volumes and approach full lung inflation, thus improving pulmonary ventilation. In addition, if these higher inspiratory volumes are achieved, the patient may, at least theoretically, have an improved ability to expel air forcefully. Thus, the marked reduction in the ability of quadriplegics to achieve full lung inflation and to expel air forcefully may be, at least in part, compensated for by the use of IPPB. Potentially, these effects, when combined with other physiotherapy manoeuvres aimed at enhancing clearance of pulmonary secretions, could decrease or reverse the respiratory complications that are associated with acute quadriparesis.

This study, although restricted by patient numbers, demonstrated a severe ventilatory impairment, reflected by the significant and severe decrements in resting static lung volumes and expiratory flow rates, associated with acute quadriparesis. The magnitude of these reductions in lung volumes are in a close agreement with those documented by Ledsome and Sharp. ${ }^{3}$ They are however, more pronounced than the values obtained in patients with chronic neuromuscular weakness affecting respiratory muscles. ${ }^{4-7}$

Overall, we found that the use of IPPB was associated with a significant improvement in lung volume whilst the treatment was actually in progress. In general, VC (but not TV) was significantly higher immediately following IPPB when compared to resting levels. It should be noted, however, that the mean increase in VC post treatment, although sufficient to achieve statis- tical significance, was of a small magnitude. The clinical significance of these results is uncertain. The improvements in lung volume during IPPB seemed to be of sufficient magnitude to be of clinical value, whereas the VC changes immediately post treatment were of such a small magnitude that their clinical value would be less certain. This area has yet to be investigated. If, as the evidence from this study suggests, IPPB does not have a clinically significant sustained effect on lung volume, it may have to be given at frequent intervals to have any beneficial effect on respiratory function. This area holds potential for further research.

IPPB may have other mechanisms of effect in acute quadriparesis. For example, IPPB, by virtue of delivering positive pressure during inspiration, may re-expand areas of atelectasis that would not be inflated by normal negative phase inspiration. Another possible effect of IPPB is that expiratory flow rates may be increased whilst IPPB is administered, and consequently forced expiratory manoeuvres enhanced. Furthermore, IPPB may improve chest wall mechanics and pulmonary compliance. These areas are open to further investigation.

\section{Acknowledgements}

This study was approved by the Human Ethics Committee of the Royal Adelaide Hospital. Special thanks to Naomi Haensel, Director of Physiotherapy, RAH, for her support of research within the department. 


\section{Stiller et al}

\section{References}

1 Carter RE (1987) Respiratory aspects of spinal cord injury measurement. Paraplegia 25: 262-266.

2 Myllynen P, Kivioja A, Rokkanen P, Wilppula E (1989) Cervical spinal cord injury: the correlations of initial clinical features and blood gas analyses with early prognosis. Paraplegia 27: 19-26.

3 Ledsome JR, Sharp JM (1981) Pulmonary function in acute cervical cord injury. Am Rev Respir Dis 124: 41-44.

4 Rose L, Geary M, Jackson J, Morgan M (1987) The effect of lung volume expansion in tetraplegia. Physiother Pract 3: 163-167.

5 Fugl-Meyer AR, Grimby G (1971) Ventilatory function in tetraplegic patients. Scand J Rehab Med 3: 151-160.

6 Huldtgren AC, Fugl-Meyer AR, Jonasson E, Bake B (1980) Ventilatory dysfunction and respiratory rehabilitation in post-traumatic quadriplegia. Eur J Respir Dis 61: 347-356.

7 McCool FD, Mayewske RF, Shayne DS, Gibson CJ, Griggs RC, Hyde RW (1986) Intermittent positive pressure breathing in patients with respiratory muscle weakness. Chest 90: 546-552.

8 De Troyer A, Deisser P (1981) The effects of intermittent positive pressure breathing on patients with respiratory muscle weakness. Am Rev Respir Dis 124: 132-137.

9 Crapo RO, Morris AH, Gardner RM (1981) Reference spirometric values using techniques and equipment that meet ATS recommendations. Am Rev Respir Dis 123: 659-664. 